\title{
THEORETICAL ANALYSIS OF SUPPORT STABILITY IN LARGE DIP ANGLE COAL SEAM MINED WITH FULLY-MECHANIZED TOP COAL CAVING
} Yucheng $\mathrm{JI}^{1}$, Yinghua $\mathrm{ZHANG}^{1}$, Zhian $\mathrm{HUANG}^{1,2,3,4 *}$,
Zhenlu $\mathrm{SHAO}^{2}$, Yukun $\mathrm{GAO}^{1}$

${ }^{1}$ State Key Laboratory of High-Efficient Mining and Safety of Metal Mines (University of Science and Technology Beijing), Ministry of Education, Beijing 100083, China

${ }^{2}$ Key Laboratory of Gas and Fire Control for Coal Mines (China University of Mining and Technology), Ministry of Education, Xuzhou 221116, China

${ }^{3}$ State Key Laboratory Cultivation Base for Gas Geology and Gas Control (Henan Polytechnic University), Jiaozuo 454000, China

${ }^{4}$ Work Safety Key Lab on Prevention and Control of Gas and Roof Disasters for Southern Coal Mines (Hunan University of Science and Technology), Xiangtan 411201, China

\begin{abstract}
Support stability is critical to ensure fully-mechanized top coal caving of large dip angle coal seam. To obtain the relations between each factor and hydraulic support stability, the mechanic model of large dip angle coal seam along face dip and strike was built to analyze support stability, including antitoppling, anti-slip, and anti-rotation of supports. The result indicates: Along the face dip, the support stability was negatively correlated with dip angle; Higher top caving means lower anti-rotation at support tail; With initial support force and working resistance of supports enhanced, the anti-slip, and antirotation stability of supports can be risen significantly. Along the strike, the critical toppling angle was proportional to dip angle, mining height, support weight, support width and support force; The critical slip angle was positive correlation with support force, friction coefficient of roof and supports. According to the results of both mechanical analysis and engineering projects, support stability in large dip angle can be risen efficiently and supports slipping, toppling and rotation can be avoided by selecting proper technical methods and equipment, like enhancing initial support force appropriately.
\end{abstract}

Keywords: large dip angle, hydraulic support, stability, coal

*Corresponding authors: huang_za@ustb.edu.cn (Z. Huang); shaozhenlucumt@sina.com (Z. Shao) doi: $10.37190 / \mathrm{msc} 202706$ 


\section{INTRODUCTION}

In China, coal resources in the large dip angle seams hold an important status in the coal energy structure. The coal seams in the large dip account for about $14.05 \%$ of the total reserves, which are widely distributed and relatively concentrated in northwest China. Over the past decades, shallow buried and near horizontal coal resources are exhausted gradually, while the fully-mechanized mining method are applied and the production efficiency is promoted dramatically. The coal seams in large dips or deeply buried, have been put more and more attention on, which is relatively difficult to be exploited (Hu et al. 2018; Lai et al. 2015; Wang et al. 2014).

In the process of coal formation, the coal seams in large dips must have experienced lots of intense tectonic activities (Liang et al. 2019; Li et al. 2017; Ma et al. 2015; Ma et al. 2011; Qian et al. 2010); It results in more faults and folds, larger variation of dips and thickness, more joints in coal and rock strata (Fang 2018; Wang et al. 2014; Wang et al. 2013). And the coal becomes more fragile to collapse. All of these makes it more difficult to exploit the coal resources reserving in seams of large dips (Wu et al. 2018; Yu 2013; Liu 2014). The mining method, applied in inclined and gently inclined coal seams, can't be used to coal seams in large dips. Some special mining method has been applied on coal seams in large dips, such as mining technology with flexible shield support, pitching oblique mining, and so on (Wang et al. 2019; Fang 2018). Recently, the coal seams in a large dip have been explored with a couple of mining methods as well as some new methods because of different occurrences.

Fully-mechanized caving will be widely-used in the future mining of coal seams in a large dip angle, which will meet the demands of higher productivity. Hydraulic support is the key equipment in fully-mechanized caving (Zhao 2019; Huang et al. 2010). If support stability could be ensured, the production efficiency and safety will increase. Under the influence of dip angle, working load of the supporting system will decrease, while external load will increase. It always results in the support system instability. Also, the probability of support slipping at working face and extrusion between supports will rise. The stability of hydraulic support is a crucial problem in mining at large dip angle coal seam with fully-mechanized top coal caving (Zhang 2011). Because the surrounding rock has a foundational influence on the workface and the supports, scholars have carried out some researches on the relationship between the surrounding rock and the support. Shi et al. investigated the solution of complete instability of surrounding rock in steeply inclined fully mechanized caving face (Shi et al. 2019). Wu has built up the R-S-F model to describe the relationship of the surrounding rock and supports (Wu 2006). Wang studied on the influence of clamping rock burst on the surrounding rock in horizontal section mining of steeply inclined extra-thick coal seam, and established the rock burst type and discriminant criterion of clamped coal mass suitable for subsection mining (Wang 2019). Wang made the research on the relationship between hydraulic supports and surrounding rock (Wang 2010). Other scholars, like Zhang DS et al. (2013), have made the similar study on 
the condition of top-caving mining method during the special mining period. In the previous researches, the fracture mode of large inclined seam roof (Liu et al. 2014), the support stability (Wu et al. 2014), the working resistance of support (Buzilo et al. 2010) were researched, which mainly focused on supports and wall rock as study object at large dip coal seam, and mainly studied the support stability along face dip. Many scholars have made contribution to figure out how the supports can work efficiently in the steeply inclined workface. There are still more works to approach a comprehensive understanding.

In this paper, the hydraulic support was selected as the study object and its stability was theoretically analyzed via judging the anti-toppling, anti-slip and tail anti-rotation along the face dip and strike. The theoretical analysis of this study will provide the basis for the design and optimization of hydraulic supports of steeply inclined fully mechanized caving face, and provide theoretical guidance for improving the stability of hydraulic supports of steeply inclined fully mechanized caving face. It is of a certain significance both in theoretical and practical aspects.

\section{STABILITY ANALYSIS OF HYDRAULIC SUPPORT AT LARGE DIG ANGLES ALONG FACE DIP}

\subsection{ANTI-TOPPLING STABILITY ANALYSIS OF SUPPORT ALONG FACE DIP}

The complexity of the stress of the support at the working surface is caused by the complex ore pressure in large dip angle caving. The stability of hydraulic support can be affected by the dip angle, degree of crushing, support moving methods, mining and caving process, hydraulic support structure and properties (Shi et al. 2019; Yuan et al. 2008; Liu 2014).

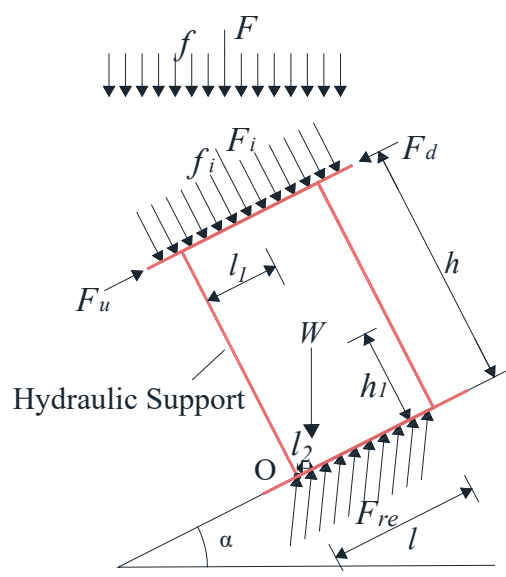

Fig. 1. Anti-toppling mechanical model of hydraulic support along face dip 
To analyze the stability of hydraulic support, a mechanical model was built, in which the hydraulic support was assumed under uniform load. The hydraulic support mechanical model of anti-toppling along face dip is shown in Fig. 1.

When the large dip coal seam is mined, the actual movement of the roof is a curve, which is close to the direction of gravity, and the force of the roof is also close to the direction of gravity, just as on Fig. 1. Considering the simplification of the mechanical model, it is simplified to the gravity direction in this paper. During the mining period, the stability of hydraulic support is affected by the pressure $F$, the support gravity $W$, the extrusion pressure $F_{u}, F_{d}$, initial support force $f_{i}$, and the supporting force $F_{r e}$. The simplified model is shown in Fig. 2. When the support is stable, the mentioned force should be in the mechanical equilibrium.

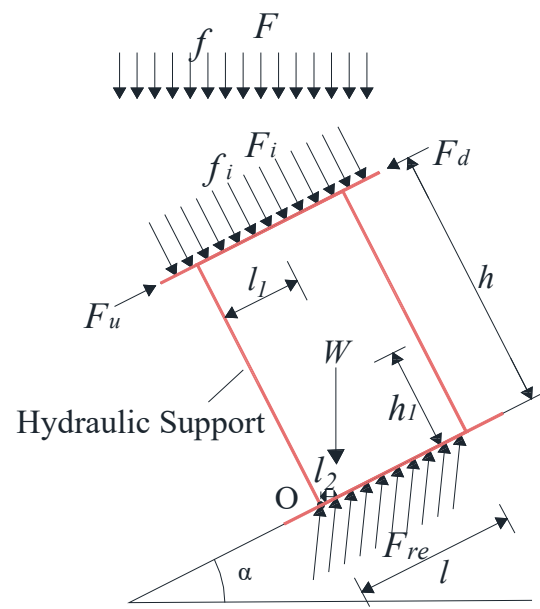

Fig. 2. Simplified anti-toppling mechanical model of hydraulic support along face dip

In the mining process, the component forces, which works on supports in each direction, change dynamically. When the point of resultant force on the support is beyond the contact surface between the support base and floor, the support will topple. When the support along the face dip is at critical equilibrium state, it means that reaction force of floor on the support, should be on the point $O$, and each overturning moment and anti-overturning moment, caused by every component force of the support to point $O$, should meet the torque limit equilibrium.

Hence, we can obtain:

$$
\begin{gathered}
F_{u} h+F h \sin \alpha=F_{d} h+F \frac{l}{2} \cos \alpha+W l_{2}, \\
l_{2}=\frac{l}{2} \cos \alpha-h_{1} \sin \alpha,
\end{gathered}
$$


where:

$h$ - height of the support,

$h_{1}$ - height of center of gravity,

$l$ - width of the support base,

$l_{2}$ - horizontal distance between gravity direction and edge of support base,

$\alpha$ - dip angle.

Due to Eq. (2), horizontal distance $l_{2}$ between gravity direction and edge of support base, has negative correlation with the dig angle $\alpha$. When the horizontal distance $l_{2}$ increases, the height of center of gravity $h_{1}$, height of the support $h$ and toppling torque of support decreases. On the other hand, anti-toppling torque increases. As a result, the stability of the support will be enhanced.

\subsection{ANTI-SLIP STABILITY ANALYSIS OF SUPPORT ALONG FACE DIP}

As shown in Fig. 3, the anti-sliding stability of support along the face dip is mainly affected by its own gravity $W$ and roof pressure $F$, whose component force along the face dip is the driving force of the support sliding down.

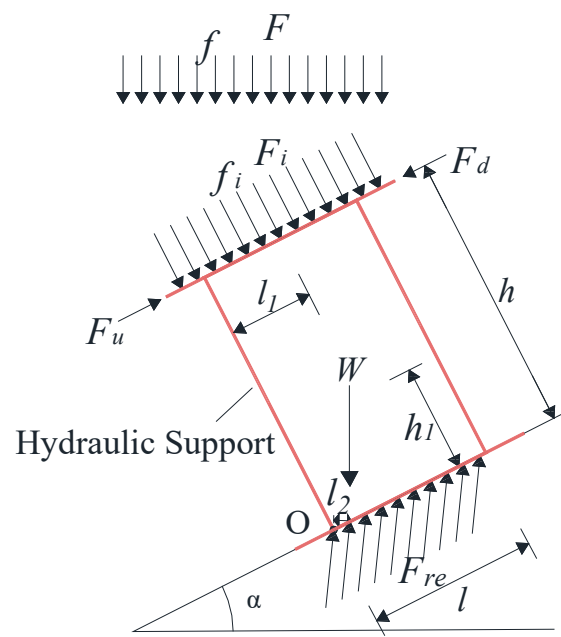

Fig. 3. Simplified anti-slip mechanic model of hydraulic supports along face dip

To ensure the anti-slip stability of support along the face dip, anti-slip fore $F_{a s}$ must be greater than slip force $F_{s}$ :

$$
F_{a s} \geq F_{s}
$$

Namely

$$
\left[(W+F) \cos \alpha+F_{i}\right] \cdot u \geq(W+F) \sin \alpha+\left(F_{s}-F_{X}\right),
$$


where:

$F_{a s}-$ anti-slip force,

$u$ - coefficient of kinetic friction.

According to Eq. (3), the existence of the initial support force only increases the anti-slide force, and has no contribution to the downward force. So, the anti-slide capacity of the support can be significantly improved if the initial support force increases.

Assume that the support is only influenced by its own gravity, and the initial support force and the roof pressure are zero. Due to the equation mentioned, we can know:

$$
W u \cos \alpha \leq W \sin \alpha \text { and } \tan \alpha \geq u \text {. }
$$

The related research shows that the friction coefficient of metal and coal seam is $0.35 \sim 0.40$ (Zhang 2011). According to the Eq. (4), the support will slip if the dig angle is more than $15^{\circ}(\tan \alpha$ is greater than the friction coefficient of metal and coal seam). So, we can draw a conclusion that the anti-slip measures should be taken if the dig angle is beyond $15^{\circ}$.

\subsection{ANTI-ROTATION STABILITY ANALYSIS OF SUPPORT TAIL ALONG FACE DIP}

When using low caving coal process, the possibility of rotation at support tail should be considered (Yuan et al. 2015). In the mining process, the component force of caving coal will affect the support tail beam. If the anti-torque is less than the torque, the tail beam will rotate and result in support skewness. The anti-rotation mechanic model of support tail beam is shown in Fig. 4.

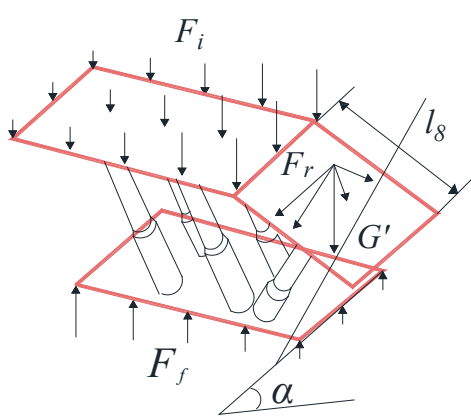

(a)

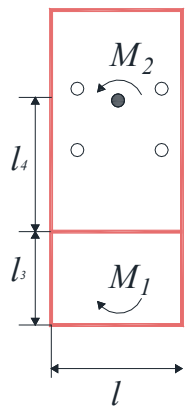

(b)

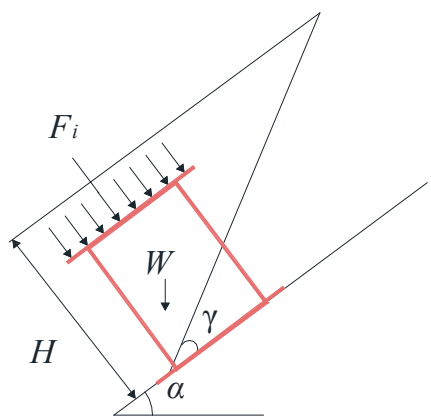

(c)

Fig. 4. Anti-rotation mechanic model of support tail beam

The torque and anti-torque, which are generated by the torsional force $F_{r}$ and the anti-torsional force $F_{a r}$, should be kept in balance. It is to ensure that the hydraulic support won't rotate. 
The gravity of the coal mass $G^{\prime}$ acts on the cover of the support beam. The torsional force of the shield beam $F_{r}$ is the component force in the coal seam dip direction of the sliding friction force that the loose coal mass acts on the cover beam. The anti-torsional force $F_{a r}$ includes the friction forces between the support, the floor and the roof. The torque of the shield beam $M_{1}$ are calculated as follows.

$$
\begin{gathered}
F_{r}=G^{\prime} u \cos \alpha \sin \theta \cos \gamma, \\
M_{1}=F_{r}\left(l_{4}+l_{3} / 2\right),
\end{gathered}
$$

where:

$\alpha+\gamma-$ stopping angle,

$\theta$ - angle between support tail beam and support beam,

$u$ - the friction coefficient of coal mass and shield beam,

$l_{3}$ - the projection length of the cover of the support beam,

$l_{4}$ - the distance from the base of the outer support to the geometric center,

$l_{8}$ - tail beam length,

$\rho$ - density of bulk coal rock mass,

$H$ - coal rock mass height.

Furtherly, we can know:

$$
M_{1}=G^{\prime} u\left(l_{4}+l / 2\right) \cos \alpha \sin \theta \cos \gamma .
$$

When the anti-torsional force $F_{a r}$ interacts with $F_{r}$, rotating point of the support is related with the roof pressure and pillar working resistance, and the distance $l_{4}$ is related with the roof pressure distribution and pillar working resistance. The related research shows that the working resistance of the support is generally greater than that of the rear column (Liu et al. 2004). According to the measurement of working resistance of the support column, assume the roof pressure in the roof is like linear distribution, the actual model can be simplified to the mechanical equilibrium model of the load on a simply supported beam in Fig. 4a, and then to determine the position between the support column of the equivalent action.

Anti-rotation moment $M_{2}$ of the friction force between the base and the top plate is used to obtain the integral of the uniform load friction torque. We can know:

$$
M_{2}=\left(\frac{2 F+W \sin \alpha}{4}\right) l_{9} u,
$$

where:

$l_{5}$ - length of beam,

$u$ - coefficient of kinetic friction between the support and the top floor.

The condition to ensure that the support does not rotate is $M_{1} \leq M_{2}$, and the antirotation stability coefficient is $R_{3}$, which can be defined as follows: 


$$
R_{3}=M_{2} / M_{1}=\frac{(2 F+W \sin \alpha) 1_{g^{9}}}{8 G^{\prime}(2 L+l) \cos \alpha \sin \theta \cos \gamma} .
$$

According to Eq. (9), when caving height is increased, the anti-rotation stability coefficient of support tail beam tends to nonlinearly decrease; When the support's working resistance increased, $R_{3}$ showed a linear increasing tendency. Hence, the greater working resistance of the support will significantly increase the anti-rotation stability of the support.

\section{STABILITY ANALYSIS OF HYDRAULIC SUPPORT AT LARGE DIG ANGLE ALONG THE STRIKE}

\subsection{ANTI-TOPPLING STABILITY ANALYSIS OF SUPPORT ALONG THE STRIKE}

The stability of hydraulic support is a common problem in the mechanical mining. The stability of hydraulic support is not only influenced by the angle of the coal seam, but also by the trend of the direction of downhill-mining or uphill-mining angle along the strike (Zhang et al. 2013; Xie et al. 2012).

When the first weighting, periodic weighting of working face, roof fall occurs in the mining process, the roof becomes more and more fragmentary with stress increasing. It results in that the roof trends to slide downward. Meanwhile, the lateral stress of the hydraulic supports will also increase under the influence of the inclined angle, which greatly reduces the stability of supports in the large dip angle coal seam. So, the mechanic model of supports along the strike in the processing of downhill-mining in Fig. 5 was built to analyze the support stability of anti-slip and anti-toppling.

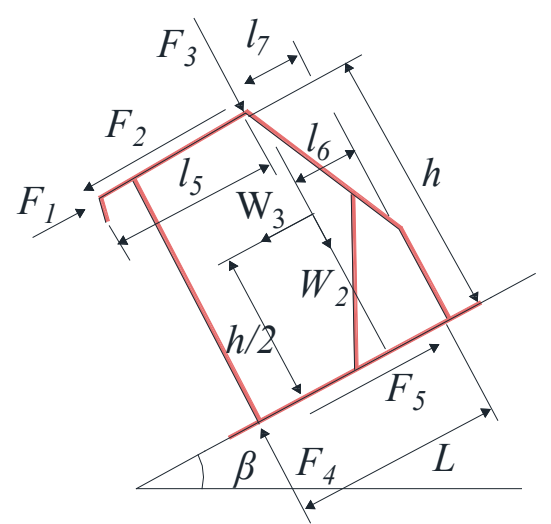

Fig. 5. Anti-toppling mechanic model of supports along the strike when downhill-mining 
Figure 5 shows anti-toppling mechanic model of supports along the strike when downhill-mining. According to the mechanical equilibrium condition, we can know that:

$$
\begin{gathered}
F_{5}+F_{1}=W_{3}+F_{2}, \\
F_{4}=W_{2}+F_{3}, \\
F_{5}=\mu F_{4}, \\
F_{3}\left(l-l_{7}\right)+\left(F_{1}-F_{2}\right) h+2 W_{2} l / 3-W_{3} h / 2=0 .
\end{gathered}
$$

Solving that equation, the critical toppling angle $\delta_{1}$ of the support along the strike can be calculated by Eq. (16):

$$
\delta_{1}=\operatorname{arcos} \frac{3 h \sqrt{W\left(16 L^{2}+9 h^{2}\right)-36 X^{2}}-24 L X}{W\left(16 L^{2}+9 h^{2}\right) \cos \alpha} .
$$

In the equation:

$$
X=L F_{3}+F_{1} h-F_{2} h-F_{4} l_{7},
$$

where:

$W_{3}$ - the component force of the support gravity $W$ along the strike,

$F_{1}$ - holding power of coal wall to support column,

$F_{2}$ - lateral force of roof,

$\mu$ - friction coefficient between the support and the rock,

$l_{5}$ - length of the roof beam,

$l_{6}$ - the distance from the center of gravity to the base of the support, $L / 3$.

$l_{7}$ - the distance from the base of the outer support to the geometric center,

$L-$ length of support base.

According to Eq. (14), if the broken roof trend to slide in the mining, the lateral force of roof $F_{1}$ along the strike has negative correlation with the critical slipping angle. And the critical angle is proportional to the dig angle, mining height, support weight, width, and support force.

\subsection{ANTI-SLIP STABILITY ANALYSIS OF SUPPORT ALONG THE STRIKE}

According to Fig. 6, the equations can be figured out as follows:

$$
\begin{gathered}
F_{5}+F_{1}=W_{3}+F_{2}, \\
F_{4}=W_{2}+F_{3}, \\
F_{5}=u F_{4} .
\end{gathered}
$$




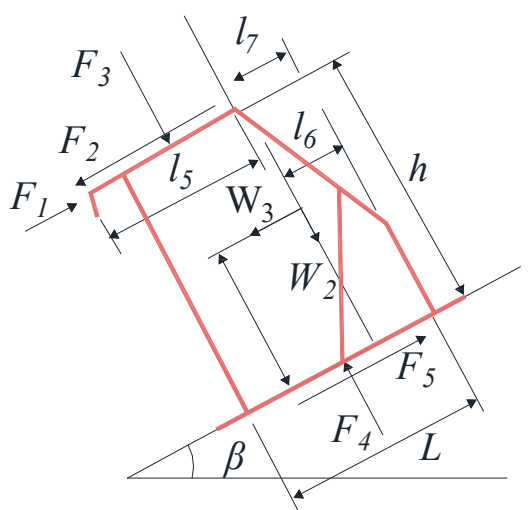

Fig. 6. Support mechanic model of anti-slip along the strike when downhill-mining

So, the critical slip angle $\delta_{2}$ can be calculated by Eq. (18):

$$
\delta_{2}=\arccos \left(\frac{\mu F_{2}-\mu F_{1}-\mu^{2} F_{s}+\sqrt{W^{2}\left(\mu^{2}+1\right)-\left(F_{1}-F-\mu F_{3}\right)^{2}}}{\left(\mu^{2}+1\right) W \cos \beta}\right) .
$$

It can be known from the Eq. (18), that raising the support force, or the friction coefficient between the support and the roof or floor, could lead to the increase of critical slip angle. Also, decreasing the support weight or the angle of coal seam strike could result in the same result. So, the anti-slip stability of supports could be enhanced by all these methods.

\section{STABILITY CONTROL OF HYDRAULIC SUPPORT IN LARGE DIPS AND ENGINEERING PROJECTS}

\subsection{STABILITY CONTROL OF HYDRAULIC SUPPORT IN LARGE DIPS}

Based on theoretical analysis of anti-toppling, anti-slip and anti-rotation both in the strike and dip in Sections 2 and 3, certain technical measures can be implemented to enhance the overall stability of hydraulic support in the fully-mechanized caving mining in large dips.

According to Eqs. (3) and (9), the fundamental measure is to increase setting load of hydraulic support and working resistance. When advancing support or no loads, a couple of supports along the workface with no loads occur to slip. By installing the jacks and anti-slip beam under support base (shown in Fig. 7), the adjoining supports can work as a whole and the setting load provided will be enough, which will strengthen the overall support stability and will be helpful for anti-slip. 


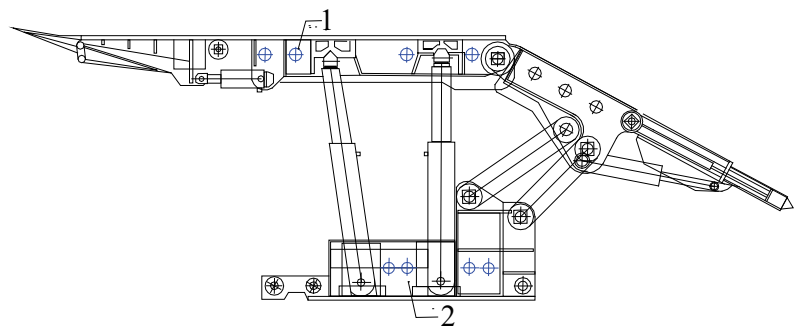

(a)

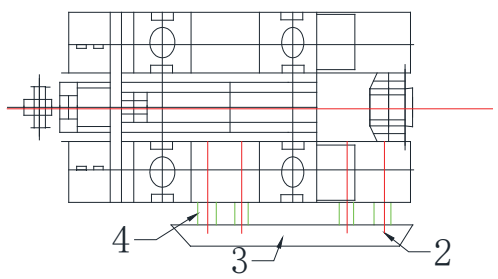

(b)

Fig. 7. Anti-slip device schematic diagram:

1 - adjusting-jack, 2 - anti-slip jack, 3 - anti-slip beam, 4 - guide rod

According to Eq. (18), it is to prevent the support from toppling and rotating that support adjusting-jack (shown in Fig. 8) should be applied on the support's roof beam. When one column of the supports loses its support and tends to topple, the adjustingjack can be used to adjust the position between the adjoining support, and keep them as a whole by making the next support as a supporting point. In the meanwhile, the anti-slip jack can prevent from losing the frictional resistance between the support and the floor.

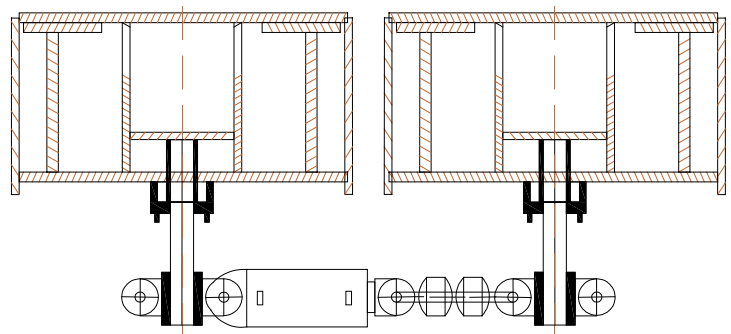

Fig. 8. Schematic diagram of adjusting-jacks

According to Eqs. (1), (3), (9) and (18), other measures are to choose supports with a wider cylinder bore or a longer load center distance, to decrease the support weight, to increase the support base's area and install anti-inclining device on top of support; It, connecting the each single support and working as a whole, will also increase the overall stability of support system.

\subsection{ENGINEERING PROJECTS}

Baodi Colliery is located in Xinjiang, China. The N01 workface retreat the coal in the steep seam with a large angle of $45^{\circ} \sim 50^{\circ}$. The depth of coal seam is from $185 \mathrm{~m}$ to $220 \mathrm{~m}$ 
with $5.6 \mathrm{~m}$ the average. The immediate roof is a thick siltstone. The basic roof is sandstone, and the direct floor is consisted of siltstone and mudstone, and the basic floor a medium sandstone. The thickness of the immediate roof is approximately $8 \mathrm{~m}$ while that of the basic roof is averagely $4 \mathrm{~m}$, and the direct roof from $3.5 \mathrm{~m}$ to $4.8 \mathrm{~m}$, the basic floor $12 \mathrm{~m}$.

A fully-mechanized longwall caving method is applied in the workface. Due to the steep angle of the coal seam, the support was in an instable situation while the face advanced. Sliding occurred sometimes.

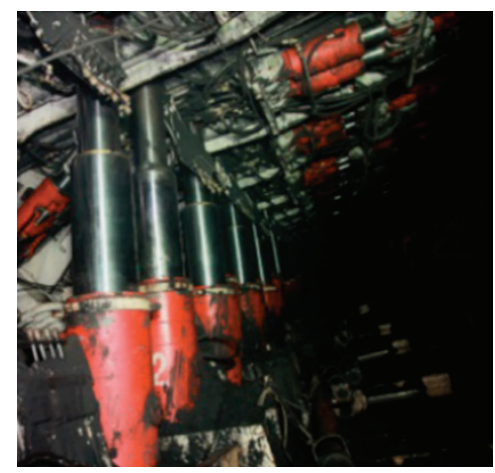

(a) Hydraulic supports

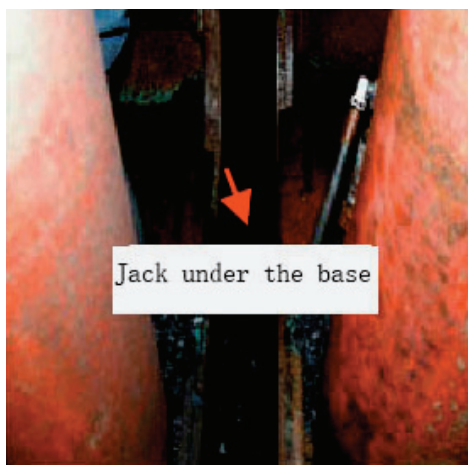

(b) Jacks under the support's base

Fig. 9. Supports with the anti-slipping jacks

According to the analysis above, measures must be applied to strengthen stability of the supports. The anti-slip device has been installed in the hydraulic support system, which is shown in Fig. 9. According to Eqs. (1) and (14), the anti-toppling and anti-slip capacity of the supports in N01 workface was significantly enhanced via increasing the support's resistance, reducing the height of the gravitational center of the support, and increasing the base length of the support. The records have shown the resistance of the jack in No. 90 support add $1245 \mathrm{KN} \sim 1700 \mathrm{KN}$ to the load of the support. The field application testifies that the result of theoretical analysis above is credible and can be applied in other workfaces of the similar geological situation.

\section{CONCLUSIONS}

(1) The mechanical models of anti-toppling, anti-slippage and anti-torsion stability of the hydraulic supports along the dip are established. When the dip angle of coal seam is larger, the stability of supports is lower. The higher the height of top coal, the lower the anti-torsion stability of the supports. Increasing initial support force and working resistance of the supports has a significant effect on the enhancement of the anti-slip stability and the anti-rotation stability of the supports. 
(2) The anti-toppling and anti-slip mechanic model along the strike were built and the equations of toppling angle and slip angle of support along the strike were derived.

(3) Based on the mechanical analysis of support stability, certain technical measures have been proposed to enhance support stability of fully-mechanized caving workface in a large dip angle, such as reasonably increasing the setting load of support, choosing the support with optimal design, adding jack under the support base and making the single support function as a whole. The engineering project's result has shown that the measures could effectively enhance the supports' stability of the workface with a large dip angle.

\section{ACKNOWLEDGEMENT}

The authors appreciate the financial support of project No. FRF-IC-19-013 provided by the Fundamental Research Funds for the Central Universities, project No. 51974015, No. 51904292 and No. 51474017 provided by the National Natural Science Foundation of China, project No. 2018 YFC0810600 provided by the National Key Research and Development Program of China, project No. 2017CXNL02 provided by the Fundamental Research Funds for the Central Universities (China University of Mining and Technology), project No. BK20180655 provided by the Natural Science Foundation of Jiangsu Province, project No. WS2018B03 provided by the State Key Laboratory Cultivation Base for Gas Geology and Gas Control (Henan Polytechnic University), and project No. E21724 provided by the Work Safety Key Lab on Prevention and Control of Gas and Roof Disasters for Southern Coal Mines of China (Hunan University of Science and Technology).

\section{REFERENCES}

BUZILO V., SERDYUK V., YAVORSKY A., 2010, A research of influence of support resistance of the stope in the immediate roof condition, New Techniques and Technologies in Mining-Proceedings of the School of Underground Mining, 127-130.

FANG J., 2018, Research on roof breaking characteristics and law of mine pressure in steep bow pseudo-inclined seam, Chongqing University, Chongqing [Dissertation].

FANG Z.Z., 2018, Up and down moving mechanism and control of false-inclined mining equipment with large mining height, Coal Mining Technology, 23 (6), 36-43.

HUANG Z.Z., REN Y.F., ZHANG H.J., 2010, Study on key technology of fully mechanized top coal caving in extra-thick soft coal seam with great dip angle, Journal of China Coal Society, 35 (11), 1878-1882.

LAI X.P., CAI M.F., REN F.H. et al., 2015, Study on dynamic disaster in steeply deep rock mass condition in Urumchi coalfield, Shock and Vibration, 10 (2), 26-35.

LI X., WANG Z., ZHANG J., 2017, Stability of roof structure and its control in steeply inclined coal seams, International Journal of Mining Science and Technology, 27 (2), 359-364.

LIANG H.R., 2019, Analysis of stability factors of support in steep upward mining medium-thick coal seam, China Mine Engineering, 48 (4), 55-59.

LIU C.Q., 2014, The movement law of the roof rock and the stability of the support in the big dip thick coal seam large mining height working face in Quandian Coal Mine, China University of Mining andTechnology, Xuzhou [Dissertation]. 
LIU C.Y., YANG J. X. et al., 2014, Destabilization regularity of hard thick roof group under the multigob, Journal of China Coal Society, 39 (3), 395-403.

LIU Z.M., CHEN Z.H., XIE J.W. et al., 2014, Stability analysis and control measures of powered supports in greater inclined full-mechanized coal seam, Journal of China Coal Society, 29 (3), 264-268.

MA F.H., SUN L., LI D., 2011, Numerical simulation analysis of covering rock strata as mining steepinclined coal seam under fault movement, Transactions of Nonferrous Metals Society of China, 21, 556-561.

MA L.Q. et al., 2015, Support stability mechanism in a coal face with large angles in both strike and dip, Journal of the Southern African Institute of Mining and Metallurgy, 115 (7), 599-606.

QIAN M.G., 2010, Ground pressure and strata control, China University of Mining and Technology, Xuzhou.

RAFAEL R.D., JAVIER T.A., 2000, Hypothesis of the multiple subsidence trough related to very steep and vertical coal seams and its prediction through profile functions, Geotechnical and Geological Engineering, 18 (4), 289-311.

HU S.X., MA L.Q., GUO J.S. et al., 2018, Support-surrounding rock relationship and top-coal movement laws in large dip angle fully-mechanized caving face, International Journal of Mining Science and Technology, 28 (3), 533-539.

SHI F.T., JIN R.Q., 2019, Solution of steeply inclined fully mechanized caving face and complete instability of rock, Coal Technology, 38 (4), 110-115.

TU H.S., TU S.H., CHEN F., 2014, Study on the deformation and fracture feature of steep inclined coal seam roof based on the theory of thin plates, Journal Mining and Safety, 31 (1), 49-54.

WANG G.F., PANG Y.H., 2015, Relationship between hydraulic supports and surrounding rock coupling and its application, Journal of China Coal Society, 140 (1), 30-34.

WANG N.B., ZHANG N., 2013, Characteristics of stope migration and roadway surrounding rock fracture for fully-mechanized top-coal caving face in steeply dipping and extra-thick coal seam, Journal of China Coal Society, 8, 1312-1318.

WANG S.W., WANG F.M., 2104, CBM development well type for steep seam in Fukang Baiyanghe mining area, Journal of China Coal Society, 9, 1914-1918.

WANG Z.Y., 2019, Mechanism of clamping rockburst in horizontal section mining of steeply inclined extra-thick coal seam, China University of Mining and Technology, Xuzhou [Dissertation].

WU F.F., LIU C.Y., LI J.W., 2014, Combination hydraulic support stability of working face in large inclined and "three-soft" thick seam, Journal of Mining and Safety Engineering, 31 (5), 721-725, 732.

WU Y.Q., 2018, Study on the floor movement law of large inclined and height working face, Xi' an University of Science and Technology, Xi'an [Dissertation].

WU Y.P., LANG D., et al., 2018, Regional fracture of top-coal along the inclined direction of fully-mechanized caving face in soft steep dipping seam, Journal of Mining and Safety Engineering, 35 (3), 553-561.

WU Y.P., LIU K.Z, YUN D.F. et al., 2014, Research progress on the safe and efficient mining technology of steeply dipping seam, Journal China Coal Society, 39 (8), 1611-1618.

WU Y.P., 2006, Keys to dynamic equations of system R-S-F and determination on working resistance of face support in steeply dipping seam mining, Journal of China Coal Society, 31 (6), 736-741.

XIE P.S., WU Y.P., WANG H.W. et al., 2010, Stability analysis of incline masonry structure and support around longwall mining face area in steeply dipping seam, Journal of China Coal Society, 37 (8), $1275-1280$.

YIN G.Z., LI X.S., GUO W.B., 2010, Photo-elastic experimental and field measurement study of ground pressure of surrounding rock of large dip angle working coalface, China Journal Rock Mech. Engineering, 29 (3), 3336-3343.

YU J.H., 2013, Research of steep seam backfill mining methods and its mechanism of surrounding rock movement, China University of Mining and Technology, Beijing [Dissertation]. 
YUAN Y., TU S.H., WANG F.T. et al., 2015, Hydraulic support instability mechanism and its control in a fully-mechanized steep coal seam working face with large mining height, Journal of Southern African Institute of Mining and Metallurgy, 115 (5), 441-447.

YUAN Y., TU S.H., DOU F.J. et al., 2008, Support instability mechanism of fully mechanized top coal caving face with steep coal seams and its control, Journal of Mining and Safety Engineering, 25 (4), 430-434.

ZHANG D.S., WU X., ZHANG W. et al., 2013, Stability analysis on support in large inclined coalface during special mining period, Journal of Mining and Safety Engineering, 30 (3), 331-336.

ZHANG Z.Y., 2011, Dynamic analysis on stability of hydraulic powered support in deep inclined fully mechanized wall and prevention slips measures, Journal of China Coal Society, 30 (7), 705-709.

ZHAO K., 2019, Study on stability and control technology of large dip angle mining support in thick coal seam with large mining height, Coal and Chemical Industry, 42 (1), 43-49. 